\title{
A novel mixed-ligand coordination polymer with pillared-layer \& ladder like structure: synthesis, crystal structure, properties study, and application as sorbent for acetaminophen extraction
}

\author{
Mahmoud. Delavar ${ }^{1 *}$, Behnaz. Afzalian ${ }^{1}$, Behrouz. Notash ${ }^{2}$ \\ ${ }^{I}$ Department of Chemistry, Payam Noor University (PNU), Tehran, Iran \\ ${ }^{2}$ Department of Chemistry, Shahid Beheshti University, G.C., Evin, Tehran, Iran \\ *Corresponding author E-mail: delavar1392@gmail.com
}

Copyright (C) 2015 Mahmoud. Delavar et al. This is an open access article distributed under the Creative Commons Attribution License, which permits unrestricted use, distribution, and reproduction in any medium, provided the original work is properly cited.

\begin{abstract}
The novel coordination polymer, $\left[\mathrm{Cd}\left(\mathrm{NO}_{3}\right)(\mathrm{P}-2)(\mathrm{pzca})\right]_{\mathrm{n}}(1)$; $[\mathrm{P}-2=$ pillar ligand $=4$, 4'-bipyridine; pzca $=2$ pyrazinecarboxylate] has been synthesized by the branched tube method under heat gradient condition and characterized by elemental analysis, FT-IR spectroscopy and powder X-ray diffraction. Compound 1 was structurally characterized by single-crystal X-ray diffraction. X-ray analysis reveals that it forms an one-dimensional covalent ladder like structure by two different bridging ligands, 4, 4'-bipy and pzca, which further significantly extends into twodimensional networks via hydrogen bonding and other weak interactions. This polymer consists of three parts: equatorial layers, the bpy ligands connect axially these layers as the pillar which result in coordination pillared-layer structure (CPL) and one dimensional pores. The application of compound 1 was studied as a sorbent for extraction of acetaminophen medicine. Acetaminophen was extracted by solid phase extraction method and monitored by UV-Vis spectrophotometer. Furthermore, the remarkable thermal stability of compound 1 has also been studied by thermal gravimetric analyses (TGA).
\end{abstract}

Keywords: Coordination Polymer; Pillared-Layer Structures; Pillar Ligand; Acetaminophene; Solid Phase Extraction.

\section{Introduction}

Coordination polymers which build up with metal ions as connectors and organic bridging ligands as linkers have been extremely studied [1], [2]. These building-block units link to the metal centers via coordination bonds and other weak chemical interactions [3]. Design and synthesis of coordination polymers depend on their special properties and applications, such as: Molecular storage, luminescence, electrical conductivity, Sensor capability, and Catalysis [3], [5]. The synthesis methods are utilized for coordination polymer productions are generally the same as to grow any crystal. These, generally include solvent layering (slow diffusion), slow evaporation, slow cooling, hydro (solvo) thermal, microwave, ultrasonic, and solvent free method [6], [14].

Many significant properties of polymers depend principally on organic linkers. The connection mode and nature of the organic linkers with two or more donor atoms such as $\mathrm{N}, \mathrm{O}$, and/or S, perform very important roles to create the infinite structures of the coordination polymers. One of the useful organic linkers is 4, 4'-bipyridine (4, 4'-bpy) with Ncontaining heterocyclic moieties, which can act as a rigid, rodlike organic building block in the self-assembly of coordination frameworks. This ligand is well known as a pillar ligand in the CPL-n series and coordination polymers which are made up with this P ligand named CPL-2 structures. Kitagawa's group originally developed the CPL-n series and also were continued these studies by Kaneko et al [15], [16].

The coordination pillared-layer structures (CPLs), is one unique representative example of porous coordination polymers (PCPs) with high designability, regularity, and flexibility. The family of porous coordination polymers 
(PCPs), which are division of "inorganic and organic hybrid polymers" are also called porous metal-organic frameworks (MOFs). The noticeable characteristics of CPLs are consequence of their potential applications in molecular storage, heterogeneous catalysis, drug delivery, and separation via sorption [17], [18].

One of the applications of separation procedure is extraction of the variety kind of medicine by MOFs structures, which are utilized as a sorbent such as polydimethylsiloxane (PDMS), polytetramethylesiloxane (PTMS), polytitaniatetramethylesiloxane [19], [20].

In this paper, we report a novel coordination pillared-layer structure; $\left[\mathrm{Cd}\left(\mathrm{NO}_{3}\right) \text { (4, 4'-bipy) (pyzca) }\right]_{\mathrm{n}} 1$; with anionic and neutral pillar mixed ligands, which is prepared by branched tube method [21]. In addition, Current research is also attracting attention towards the use of polymer as a sorbent for extraction and determination of medicine for the first time that have not reported before.

Acetaminophen medicine was extracted by solid phase extraction method (SPE). Acetaminophen (paracetamol,N-(4hydroxyphenyl)acetamide, belongs to the most frequently used drugs worldwide. Acetaminophen is used as an analgesic and antipyretic agent. It is commonly used for the easement of fever, headache, and other minor aches and pains. Variety of analytical methods have been used for extraction of acetaminophen such as titrimetry, spectrophotometry, liquid chromatography, and electrochemical determination [22], [25] which consist of solid phase extraction, high pressure liquid chromatography, high-performance liquid chromatography, and Gas ChromatographyMass Spectrometry [26], [28].

\section{Experimental}

\subsection{Materials and instrumentation}

$\mathrm{Cd}\left(\mathrm{NO}_{3}\right) \cdot 3 \mathrm{H}_{2} \mathrm{O}$, 2-pyrazinecarboxylic acids (Hpzca), 4, 4'-bipyridine (4, 4'-bipy) were purchased form Merck company. All solvent were of analytical grade and was used without further purification. Infrared measurements (KBr pellets) were carried out on a Shimadzu FT-IR spectrometer. Thermo-gravimetric analyses (TGA) were performed under air atmosphere with a heating rate of $10^{\circ} \mathrm{C}$ min- 1 using Shimadzu TGA-50 thermal analyses. Elemental analyses were carried out on a Thermo Finning Flash EA 1112 CHN elemental analyzer. X-ray powder diffraction (PXRD) measurements were performed with a Philips X'pert diffractometer. The extraction of medicine was detected by Shimadzu-2550 UV-Vis spectrophotometer.

\subsection{Synthesis of $\left[\mathrm{Cd}\left(\mathrm{NO}_{3}\right)\left(4,4^{\prime} \text {-bipy }\right)(\text { pyzca })\right]_{n}(1)$}

To isolate suitable single crystal of compound 1, $\mathrm{Cd}\left(\mathrm{NO}_{3}\right)_{2} \cdot 3 \mathrm{H}_{2} \mathrm{O}$ (one mmol, $0.308 \mathrm{~g}$ ), Hpzca (one mmol, $0.241 \mathrm{~g}$ ), bipy $(1.5 \mathrm{mmol}, 0.256 \mathrm{~g})$ were placed in the main arm of a branched tube. $\mathrm{MeOH}$ was carefully added to fill both arms. The tube was sealed and immersed in an oil bath at $60{ }^{\circ} \mathrm{C}$ while the other arm of the tube was kept at ambient temperature. After 1-2 days, colorless crystals were deposited in the branched arm. The crystals were isolated, filtered off, washed with acetone and ether and dried in air. Yeild: 45.50\%. Anal. Calcd for C15H11CdN5O5: C, 39.71; H, 2.44; N, 15.44. Found: C, 39.12; H, 2.56; N, 15.78. IR (cm-1) selected bands: 432(w), 489(w), 628(m), 732(w), 806(m), 1018(w), 1045(w), 1072(w), 1157(w), 1218(w), 1384(vs), 1488(w), 1535(w), 1573(m), 1616(s), 3055(w), 3417(b).

\subsection{Solid phase extraction of acetaminophen}

Acetaminophen $\left(10^{-3} \mathrm{M}\right)$ was solved in $\mathrm{H}_{2} \mathrm{O}(10 \mathrm{~mL})$ and kept for $1 \mathrm{hr}$ in an ultrasonic bath. The coordination polymer $(0.1 \mathrm{~g})$ was added until the medicine solution and was sonicated for 30 minimums again. The sample was centrifuged subsequently at $3000 \mathrm{rpm}$ for 10 minimums. After centrifuging, the initial solution and the solution after extraction were analyzed by UV-Vis spectrophotometer and confirmed the absorption of medicine.

\subsection{X-ray crystal structure determination}

The X-ray diffraction measurement was made on a STOE IPDS-II diffractometer with graphite monochromated Mo-K $\alpha$ radiation $(\lambda=0.71278 \AA)$. For $\left[\mathrm{Cd}\left(\mathrm{NO}_{3}\right)\left(4,4^{\prime} \text {-bipy) (pyzca) }\right]_{\mathrm{n}} 1\right.$, colorless block shape, crystal was chosen, using a polarizing microscope which mounted on a glass fiber for data collection. Cell constants and orientation matrices for data collection were obtained by least-squares refinement of diffraction data from 4695 unique reflections. Data were collected to a maximum $2 \theta$ value of $58.5^{\circ}$ in a series of $\omega$ scans in $1^{\circ}$ oscillations and integrated using the Stoe XAREA [29] software package. The data were corrected for Lorentz and Polarizing effects. The structure was solved by direct methods [30] and subsequent difference Fourier maps and then refined on F2 by a full-matrix least-squares procedure, using anisotropic displacement parameters [31]. All aromatic hydrogen atoms were added in idealized positions. The atomic factors were taken from the International Tables for X-ray Crystallography [32]. All refinements were performed using the X-STEP32 crystallographic software package [33]. 


\section{Results and discussion}

One-dimensional pillared-layer ladder like structure of novel coordination polymer was synthesized by branched tube (hydrothermal) method. In this procedure, utilized the 4, 4'-bipy pillar ligand and pyrazinecarboxilate, result's mixedligand pillared-layer polymer. This structure was characterized by CHN analysis, TGA, PXRD and IR. The pillaredlayer structure was utilized as a sorbent for extraction of acetaminophen. The extraction of acetaminophen was confirmed by UV-Vis spectrophotometer.

\subsection{Crystallographic description of complexes}

The single-crystal X-ray structural analysis reveals that the structure of compound 1(Table 1) is a one-dimensional ladder like network based on binuclear cd block with mixed pyrazincarboxylate anion, nitrate molecule and 4,4'-bpy. There is one crystallographically independent $\mathrm{Cd}(\mathrm{II})$ atom in the asymmetric unit of the coordination polymer which is coordinated to one oxygen and one nitrogen atom from one bidentate pzca ligand, one nitrogen atom from one 4,4'-bpy molecule and two oxygen atoms from one nitrate molecule (Fig. 1).

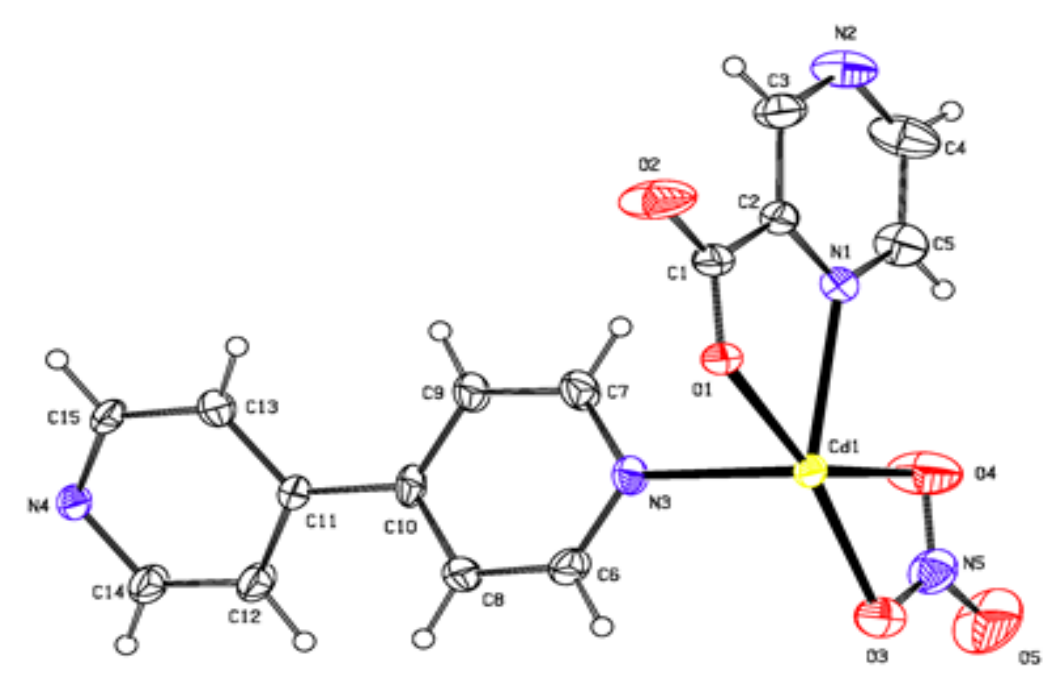

Fig. 1: ORTEP Diagram of the Asymmetric Unit of $\left[\mathrm{Cd}\left(\mathrm{NO}_{3}\right)(4,4 \text { '-bipy) (pyzca) }]_{\mathrm{n}}\right.$ Coordination Polymer. Thermal Ellipsoids are drawn at $30 \%$ Probability Level.

As it has shown in a view of the coordination sphere around Cd atoms in Fig. 2, each Cd (II) atom displays a sevencoordination number with pentagonal bipyramidal geometry by considering to connection of bridging oxygen atom (O1) of pzca from adjacent cd atom. As for the fundamental unit, $\mathrm{Cd}$ atom has six coordination numbers plus another one coordination number from bridging oxygen atom $(\mathrm{O} 1)$ of adjacent chain $(\mathrm{Cd}(1)-\mathrm{Oc}(1)=2.314 \AA)$.

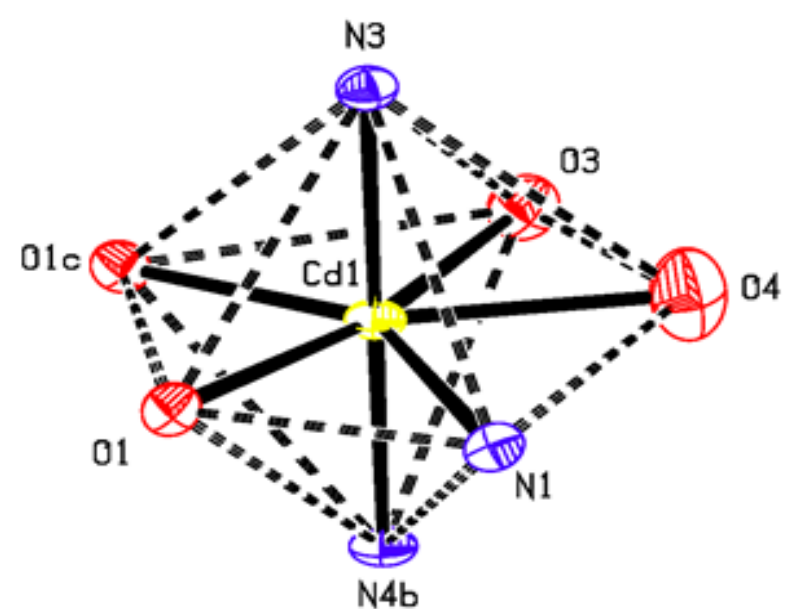

Fig. 2: View of the Coordination Sphere around Cd Atoms in $\left[\mathrm{Cd}\left(\mathrm{NO}_{3}\right)\left(4,4^{\prime} \text {-bipy) (pyzca) }\right]_{\mathrm{n}}\right.$ Coordination Polymer. Thermal Ellipsoids are drawn at $30 \%$ Probability Level.

The $\mathrm{Cd}(1)$ center coordinates to one oxygen atom $(\mathrm{Cd}(1)-\mathrm{O} 1=2.383 \AA)$ and one nitrogen atom $(\mathrm{Cd}(1)-\mathrm{N} 1=2.443 \AA)$ of one chelating carboxylate group, two oxygen atoms $(\mathrm{O} 3, \mathrm{O} 4)$ of one nitrate molecule $(\mathrm{Cd}(1)-\mathrm{O} 3=2.400 \AA$, $\mathrm{Cd}(1)-$ 
$\mathrm{O} 4=2.586 \AA)$, two nitrogen atoms $(\mathrm{Cd}(1)-\mathrm{N}(3)=2.320 \AA, \mathrm{Cd}(1)-\mathrm{N}(4)=2.586 \AA)$ of different 4,4 '-bpy ligands. The $\mathrm{Cd}-\mathrm{O}$ bond distances are in the range of 2.383-2.586 $\AA$ and the $\mathrm{O}-\mathrm{Cd}$ (1)-O bond angles vary from 144.190 to 165.91 and the $\mathrm{Cd}-\mathrm{N}$ distance are in the range of 2.320-2.443 $\AA$. Such two \{CdN3O3\} pseudo octahedral are connected together to form a binuclear cd building unit via two bridging oxygen atom. Repeating of these connections results the one-dimensional ladder like structure, which is confirmed with crystal packing analysis (Fig. 3) [34].

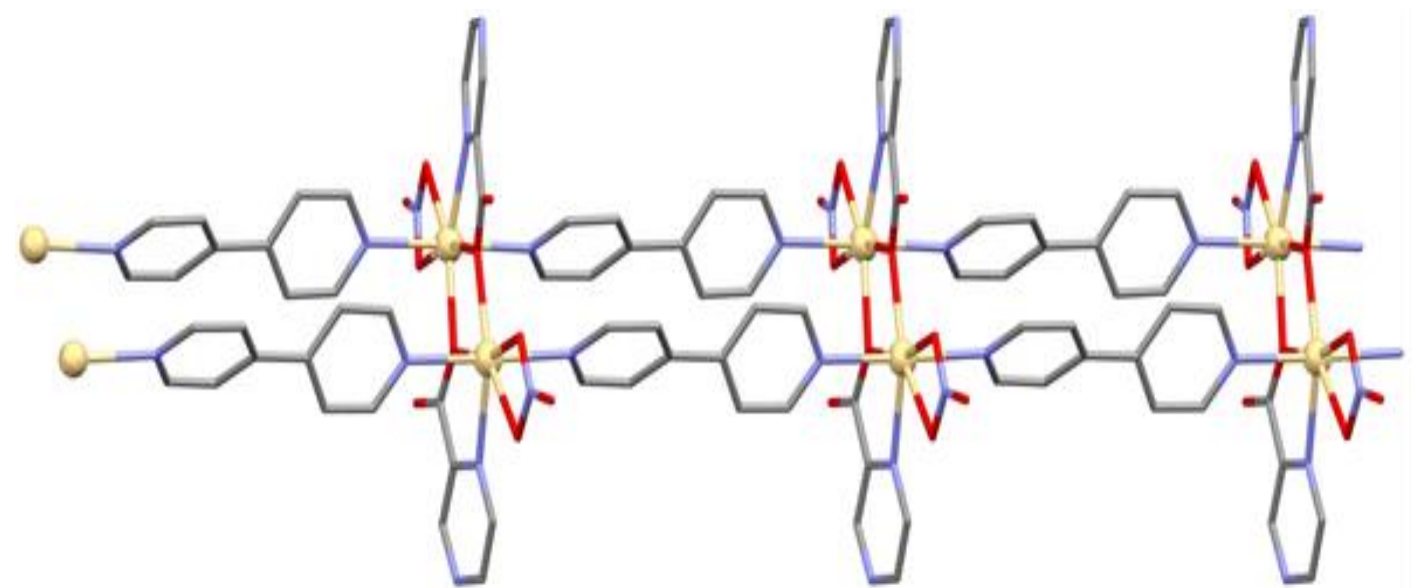

Fig. 3: Ladder-Like One-Dimensional Coordination Structure in $\left[\mathrm{Cd}\left(\mathrm{NO}_{3}\right)\left(4,4^{\prime} \text {-bipy) (pyzca) }\right]_{\mathrm{n}}\right.$ Hydrogen Atoms Have Been Omitted for Clarity.

In this structure to each $\mathrm{Cd}$ atom connect one nitrate molecule and one pyzca as a chelating agent at equatorial position, which result an equatorial plane. Furthermore, two equatorial plane of $\left[\mathrm{Cd}\left(\mathrm{NO}_{3}\right)\right.$ (pzca)] connect together via two oxygen bridging atoms result the total equatorial layer in each unit (Fig. 4). The role of pillar ligand is connecting these equatorial layers to each other axially, which results pillared-layer structure (Fig. 5) .One-dimensional parallel ladder like chains of polymer, connect to each other via hydrogen bonding and other weak interactions to result twodimensional networks.

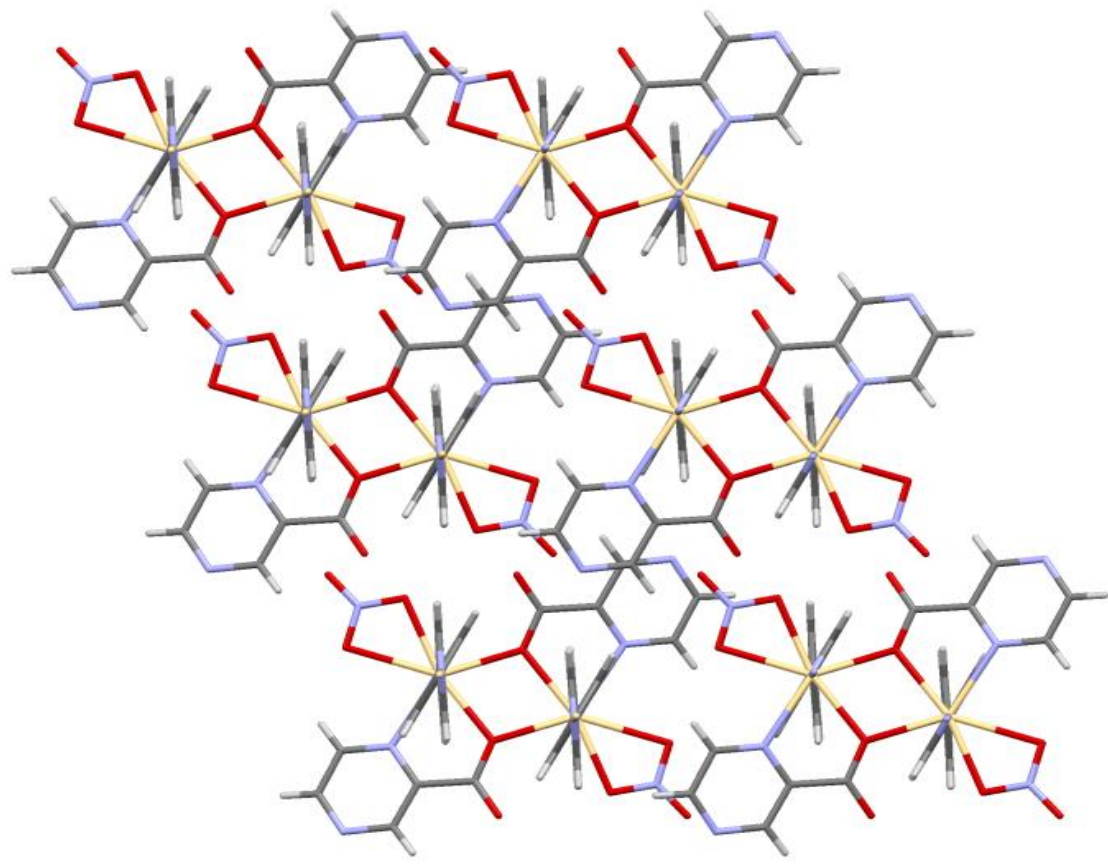

Fig. 4: Equatorial Layer of Compound 1 along $C$ Axis. 


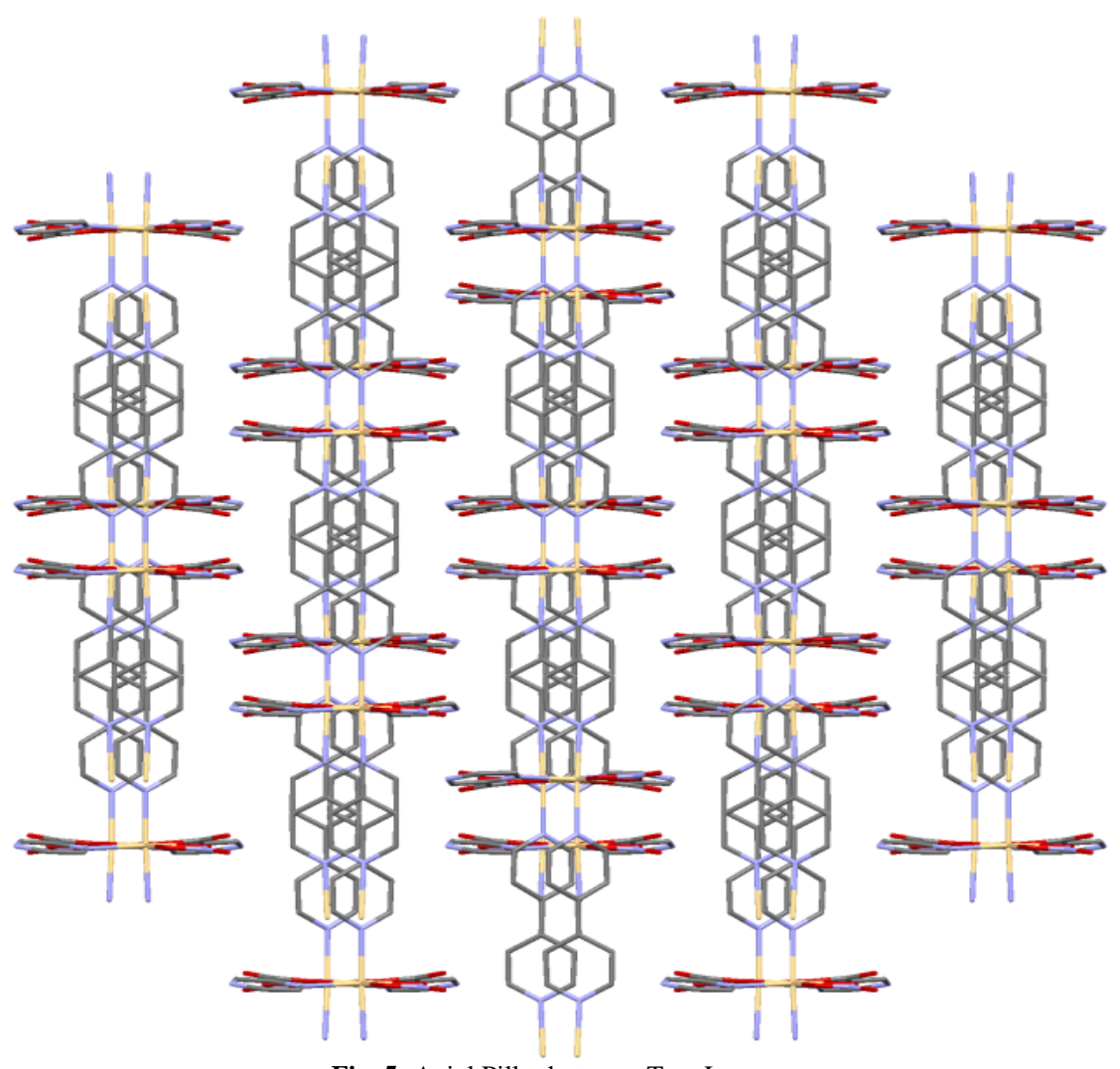

Fig. 5: Axial Pillar between Two Layers.

The crystal data and selected bond lengths and angles are listed in Table 1and 2 which they are in good agreement with similar reports [35]. In the crystal structure of $\left[\mathrm{Cd}\left(\mathrm{NO}_{3}\right) \text { (bipy) (pzca) }\right]_{\mathrm{n}}$, There are several $\mathrm{C}-\mathrm{H} \cdots \mathrm{N}$ and $\mathrm{C}-\mathrm{H} \cdots \mathrm{O}$ hydrogen bonding, which are listed in Table 3.

Table 1: Crystal Data for Coordination Polymer.

\begin{tabular}{|c|c|}
\hline Complex & {$\left[\mathrm{Cd}\left(\mathrm{NO}_{3}\right) \text { (bipy) (pzca) }\right]_{n}{ }^{\mathrm{a}}$} \\
\hline Empirical formula & C15H11N5O5Cd \\
\hline Formula weight & 453.70 \\
\hline Temperature (K) & 298(2) \\
\hline Wavelength $(\AA)$ & 0.71069 \\
\hline Crystal system & Monoclinic \\
\hline Space group & $\mathrm{C} 2 / \mathrm{c}$ \\
\hline $\mathrm{a}(\AA)$ & 16.797(3) \\
\hline b $(\AA)$ & $11.714(2)$ \\
\hline c $(\AA)$ & $19.632(4)$ \\
\hline$\beta\left(^{\circ}\right)$ & $114.86(3)$ \\
\hline Volume $(\AA ̊ 3)$ & $3504.9(14)$ \\
\hline $\mathrm{Z}$ & 8 \\
\hline Density (calculated) (g/cm3) & 1.720 \\
\hline Absorption coefficient (mm-1) & 1.283 \\
\hline $\mathrm{F}(000)$ & 1792 \\
\hline Crystal size (mm3) & $0.20 \times 0.10 \times 0.08$ \\
\hline Theta range for data collection $\left({ }^{\circ}\right)$ & $2.19-29.25$ \\
\hline Reflections collected & 12044 \\
\hline Independent reflections & $4695[$ Rint $=0.0740]$ \\
\hline Absorption correction & Numerical \\
\hline Maximum and minimum transmission & 0.9043 and 0.7835 \\
\hline Data/restraints/parameters & $4695 / 0 / 235$ \\
\hline Goodness-of-fit on F2 & 0.856 \\
\hline$R$ indices $[I>2 \sigma(I)]$ & $\mathrm{R} 1=0.0438, \mathrm{wR} 2=0.0635$ \\
\hline $\mathrm{R}$ Indices (all data) & $\mathrm{R} 1=0.1050, \mathrm{wR} 2=0.0733$ \\
\hline Largest difference peak, hole (e Å 3) & 0.846 and -0.497 \\
\hline
\end{tabular}


Table 2: Selected Bond Lengths $(\AA)$ and Angles $\left({ }^{\circ}\right)$ for Compound $\left[\mathrm{Cd}\left(\mathrm{NO}_{3}\right) \text { (bipy) (pzca) }\right]_{\mathrm{n}}{ }^{\mathrm{a}}$.

\begin{tabular}{llll}
\hline $\mathrm{Cd}(1)-\mathrm{N}(1)$ & $2.443(3)$ & $\mathrm{Cd}(1)-\mathrm{O}(1) \# 2$ & $2.314(3)$ \\
\hline $\mathrm{Cd}(1)-\mathrm{N}(3)$ & $2.320(3)$ & $\mathrm{Cd}(1)-\mathrm{N}(4) \# 3$ & $2.320(3)$ \\
$\mathrm{Cd}(1)-\mathrm{O}(1)$ & $2.383(3)$ & $\mathrm{Cd}(1)-\mathrm{O}(3)$ & $2.400(3)$ \\
$\mathrm{Cd}(1)-\mathrm{O}(4)$ & $2.586(4)$ & $\mathrm{O}(1)-\mathrm{Cd}(1) \# 2$ & $2.314(3)$ \\
$\mathrm{N}(4)-\mathrm{Cd}(1) \# 1$ & $2.320(3)$ & $\mathrm{O}(1) \# 2-\mathrm{Cd}(1)-\mathrm{N}(3)$ & $78.89(13)$ \\
$\mathrm{O}(1) \# 2-\mathrm{Cd}(1)-\mathrm{N}(4) \# 3$ & $90.20(13)$ & $\mathrm{O}(1) \# 2-\mathrm{Cd}(1)-\mathrm{O}(1)$ & $88.44(9)$ \\
$\mathrm{N}(3)-\mathrm{Cd}(1)-\mathrm{N}(4) \# 3$ & $178.09(12)$ & $\mathrm{N}(3)-\mathrm{Cd}(1)-\mathrm{O}(1)$ & $94.06(10)$ \\
$\mathrm{N}(4) \# 3-\mathrm{Cd}(1)-\mathrm{O}(1)$ & $92.88(14)$ & $\mathrm{O}(1) \# 2-\mathrm{Cd}(1)-\mathrm{O}(3)$ & $139.43(11)$ \\
$\mathrm{O}(1)-\mathrm{Cd}(1)-\mathrm{O}(3)$ & $165.91(9)$ & $\mathrm{O}(1) \# 2-\mathrm{Cd}(1)-\mathrm{N}(1)$ & $89.32(13)$ \\
$\mathrm{N}(3)-\mathrm{Cd}(1)-\mathrm{N}(1)$ & $92.46(13)$ & $\mathrm{N}(4) \# 3-\mathrm{Cd}(1)-\mathrm{N}(1)$ & $126.44(11)$ \\
$\mathrm{O}(1)-\mathrm{Cd}(1)-\mathrm{N}(1)$ & $67.64(10)$ & $\mathrm{O}(3)-\mathrm{Cd}(1)-\mathrm{N}(1)$ & $143.93(9)$ \\
$\mathrm{O}(1) \# 2-\mathrm{Cd}(1)-\mathrm{O}(4)$ & $144.19(10)$ & $\mathrm{O}(1)-\mathrm{Cd}(1)-\mathrm{O}(4)$ & \\
\hline
\end{tabular}

Asymmetry codes: \#1: $\mathrm{x}, \mathrm{y}-1, \mathrm{z} ; \# 2$ : $-\mathrm{x}, \mathrm{y},-\mathrm{z}+3 / 2 ; \# 3: \mathrm{x}, \mathrm{y}+1, \mathrm{z}$.

Table 3: Geometrical Parameters of Hydrogen Bonds in $\left[\mathrm{Cd}\left(\mathrm{NO}_{3}\right) \text { (bipy) (pzca) }\right]_{\mathrm{n}}{ }^{\mathrm{a}}$

\begin{tabular}{lllll}
\hline $\mathrm{D}-\mathrm{H} \ldots \mathrm{A}$ & $\mathrm{D}-\mathrm{H} / \AA$ & $\mathrm{H} \ldots \mathrm{A} / \AA$ & $\angle \mathrm{DHA} /{ }^{\circ}$ & $\mathrm{D} \ldots \mathrm{A} / \AA$ \\
\hline $\mathrm{C}(15)-\mathrm{H}(15) \ldots \mathrm{N}(2) \# 4$ & 0.93 & 2.48 & $3.215(5)$ & 130.7 \\
$\mathrm{C}(12)-\mathrm{H}(12) \ldots \mathrm{O}(3) \# 5$ & 0.93 & 2.59 & $3.459(6)$ & 154.9 \\
$\mathrm{C}(12)-\mathrm{H}(12) \ldots \mathrm{O}(2) \# 6$ & 0.93 & 2.49 & $3.180(6)$ & 130.8 \\
$\mathrm{C}(5)-\mathrm{H}(5) \ldots \mathrm{O}(4)$ & 0.93 & 2.35 & $3.004(6)$ & 127.2 \\
\hline
\end{tabular}

Asymmetry codes: \#4: $-\mathrm{x}+1 / 2,-\mathrm{y}+3 / 2,-\mathrm{z}+2$; \#5: $-\mathrm{x}-1 / 2, \mathrm{y}-1 / 2,-\mathrm{z}+3 / 2 ; \# 6: \mathrm{x}-1 / 2, \mathrm{y}-1 / 2, \mathrm{z}$.

\subsection{FT-IR spectra}

The most important IR frequencies attributed to the vibrations of free acid, 4,4-bpy, and single crystal of compound 1 are reported in Table 4. The weak bands at $848 \mathrm{~cm}^{-1}$ for Hpzca, 815 and $786 \mathrm{~cm}^{-1}$ for 4,4'-bpy, and 848 and $794 \mathrm{~cm}^{-1}$ for the compound 1 , result from the aromatic skeleton vibrations of the pyrazine and pyridine rings. Some moderately and weak intense bands appeared in the $400-500 \mathrm{~cm}^{-1}$ region are assigned to new $v(\mathrm{M}-\mathrm{N})$ and $v(\mathrm{M}-\mathrm{O})(\mathrm{M}=\mathrm{Cd})$ bands, which further suggest bond formation between the metal and $\mathrm{N}$ - and $\mathrm{O}$ - donors of the ligand [36].

Table 4: Important FT-IR Data for Nano-Sized, Single Crystal of Complex 1, Hpzca and 4, 4'-bpy $\left(\mathrm{Cm}^{-1}\right)$.

\begin{tabular}{|c|c|c|c|c|c|c|c|c|}
\hline & $v(\mathrm{C}-\mathrm{H})$ & $v(\mathrm{COOH})$ & $v(\mathrm{C}-\mathrm{C})$ & $\operatorname{vas}(\mathrm{C}=\mathrm{O})$ & $\operatorname{vs}(\mathrm{C}=\mathrm{O})$ & $v(\mathrm{C}-\mathrm{O})$ & $v(\mathrm{M}-\mathrm{O})$ & $v(\mathrm{M}-\mathrm{N})$ \\
\hline 4,4'-bpy & 3024 & - & 1485 & - & - & - & - & - \\
\hline Hpyzca & 3062 & 1720 & 1460 & - & - & 1049 & - & - \\
\hline crystal compound 1 & 3055 & - & 1488 & 1616 & 1384 & 1045 & 563 & $432-489$ \\
\hline
\end{tabular}

The IR spectra of compound one displays a band at $1616 \mathrm{~cm}^{-1}$ which is attributed to the asymmetric stretching vibration of $\mathrm{C}=\mathrm{O}$ group of pzca and the bands at 1384 and $1350 \mathrm{~cm}^{-1}$ refer to symmetric stretching vibration of carboxyl group, respectively[37]. The separation [vas (COO-) - vs (COO-)] for compound $1\left(232 \mathrm{~cm}^{-1}\right)$ indicating that the COO - of pzca coordinated to $\mathrm{Cd}$ in a mono dentate mode [38]. Therefore, the absence bands in the region $1690-1730 \mathrm{~cm}^{-1} \mathrm{was}$ indicated complete deprotonation of Hpzca molecule. The wave number separation [vas (N-O) - vs (N-O)] Indicating that coordinated nitrate group is in a chelating mode which can be proved by their crystal structural determination [39]. These data $\mathrm{Cd}$ atoms was coordinated to ligands through nitrogen and oxygen of the heterocyclic.

\subsection{Thermal analysis}

The thermal gravimetric analysis of $\left[\mathrm{Cd}\left(\mathrm{NO}_{3}\right) \text { (bipy) (pzca) }\right]_{\mathrm{n}}$, were carried out between $30-800{ }^{\circ} \mathrm{C}$ under air atmosphere, (Fig. 6). The TGA curve of compound 1 displayed three decomposition steps that occurred at $42.13{ }^{\circ} \mathrm{C}$, 150-400 ${ }^{\circ} \mathrm{C}$ and $400-550{ }^{\circ} \mathrm{C}$ respectively. The first decomposition step was released ca. $2.41 \mathrm{wt} \%$ of its mass at seven minimums with the rate mass loss about $0.014 \mathrm{mg} / \mathrm{min}$. The second decomposition step at $150-400{ }^{\circ} \mathrm{C}$ lost ca. $43.69 \mathrm{wt}$ $\%$ at $25 \mathrm{~min}$ with rate mass loss about $0.07 \mathrm{mg} / \mathrm{min}$. The final decomposition occurred between $400-550{ }^{\circ} \mathrm{C}$ with a mass loss of $25.85 \%$ at $15 \mathrm{~min}$ with rate mass loss about $0.07 \mathrm{mg} / \mathrm{min}$. Total decomposition which is between $30-550{ }^{\circ} \mathrm{C}$, was $4.216 \mathrm{mg}(71.67 \%)$ due to the loss of ligand species. Decomposition was completed at $460{ }^{\circ} \mathrm{C}$ and the mass loss calculations showed that the final decomposition product was $\mathrm{CdO}$. This curve played that compound 1is air stable and has high thermal stability upper than $300{ }^{\circ} \mathrm{C}$. 


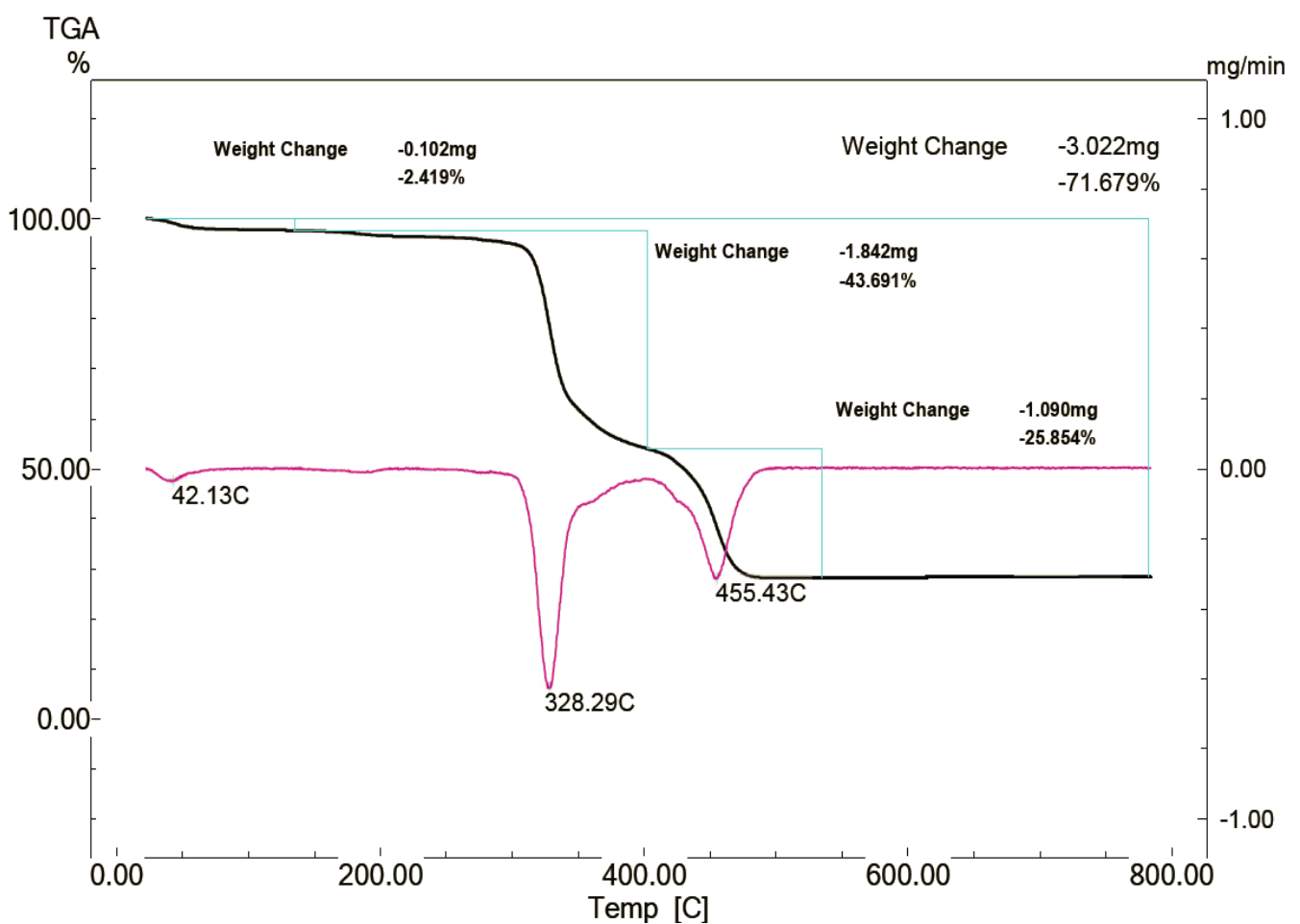

Fig. 6: The TGA of Single Crystal of Compound 1.

\subsection{X-ray diffraction}

PXRD measurement was performed on the compound 1 prepared to utilize the hydrothermal methods (Fig. 7). The observed PXRD patterns are also in agreement with the simulated ones from the single-crystal diffraction data.

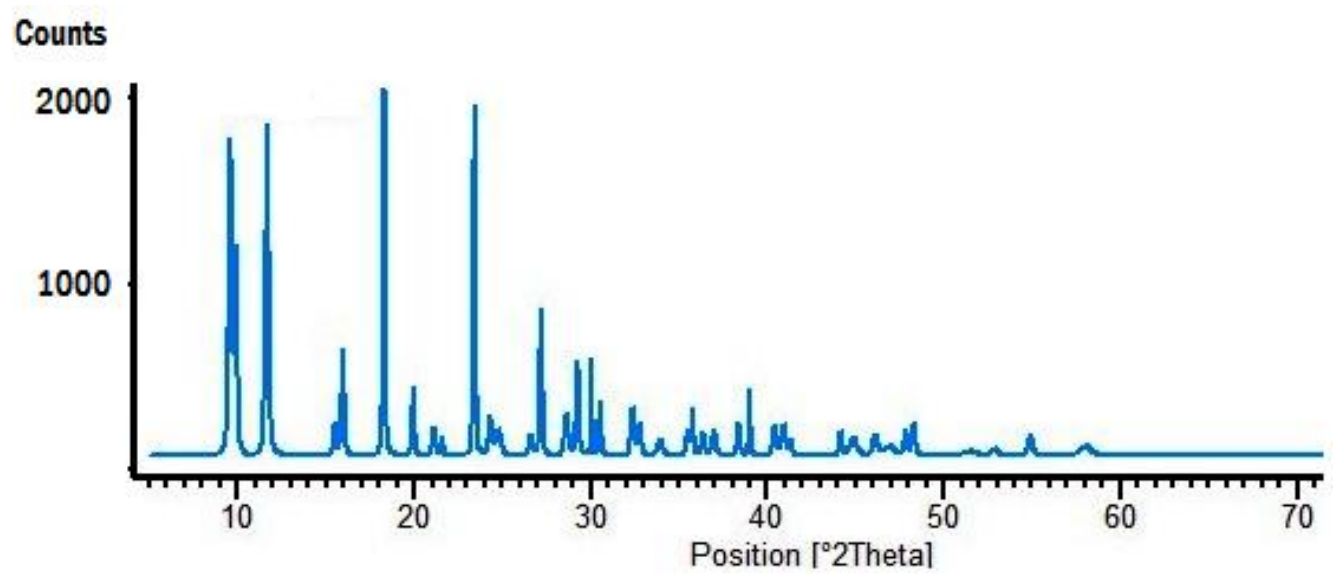

Fig. 7: This Is the XRD Pattern of Compound 1.

\subsection{Extraction analysis}

The aim of this report is the development a simple and sensitive UV-Vis spectrophotometer method for separation and quantifying of acetaminophen medicine (Fig. 8).<smiles>CC(=O)Nc1ccccc1</smiles> 
The utilized method in our extraction procedure is simple, sensitive, and time consuming without using a lot of solvents can be applied for determination of each drug. Coordination polymer as a sorbent showed the highest efficiency in extraction of acetaminophen and UV-Vis spectrophotometer confirmed the results. For extraction, the compound 1 as a sorbent was immersed into the sample solution and then acetaminophen molecules travel from the donor phase to the extractor phase. The absorption spectra was recorded using a UV-Visible spectrophotometer. Signals were monitored at 254-257 nm. The separation of acetaminophen medicine before, and after extraction is represented in Fig. 9.

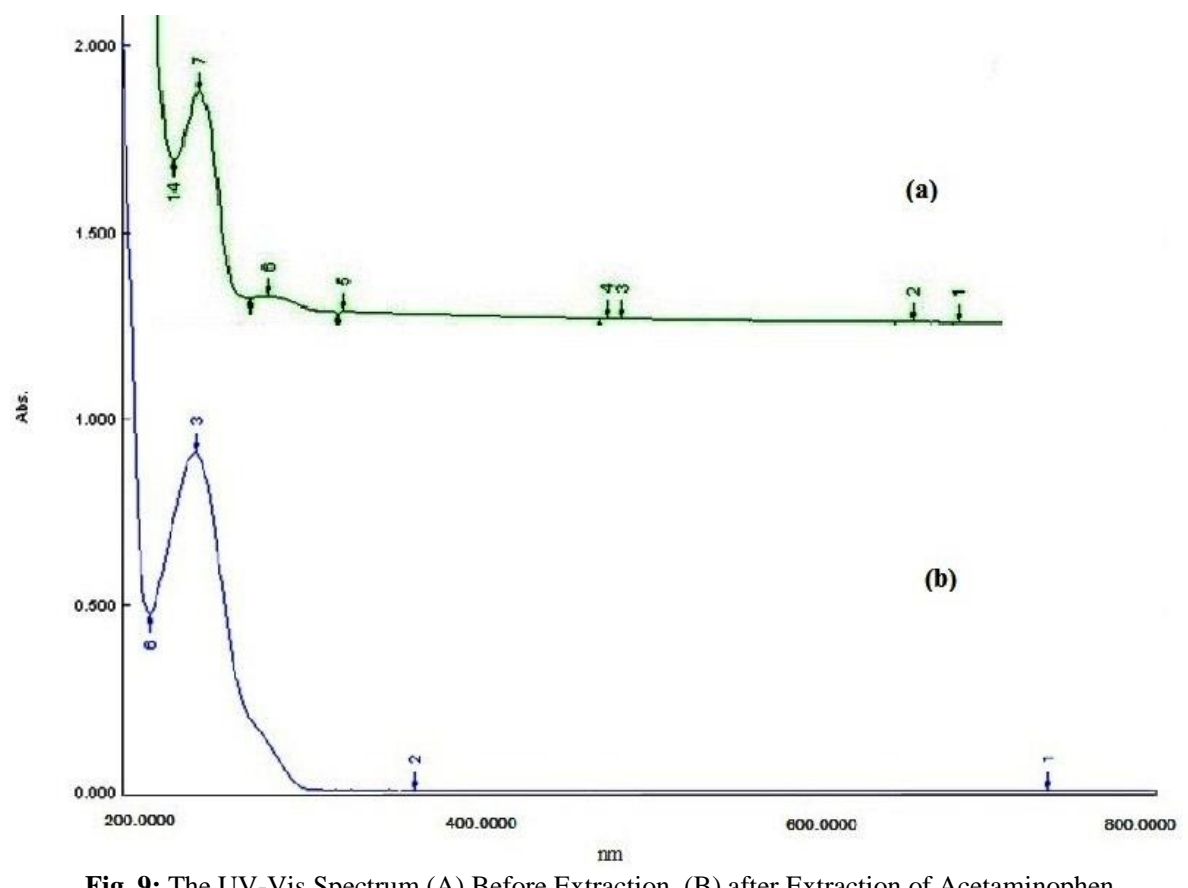

The polymer structure plays the main role of this extraction as a porous solid phase for adsorption of medicine. This structure has one-dimensional channel pores that result of distance between bipy ligands at two adjacent chains, but by considering to hydrogen bonding and resulting a supramolecular network, we observe new added one-dimensional channels in the structure which is made of interaction between two adjacent ladder chain (Fig. 10). Presence of these channels, hydrogen bonding, and other weak interactions between the structure of medicine and the structure of polymer caused to efficiency extraction of acetaminophen. Another advantage is determination of trace amount of medicine by simple method and inexpensive equipment at low time.

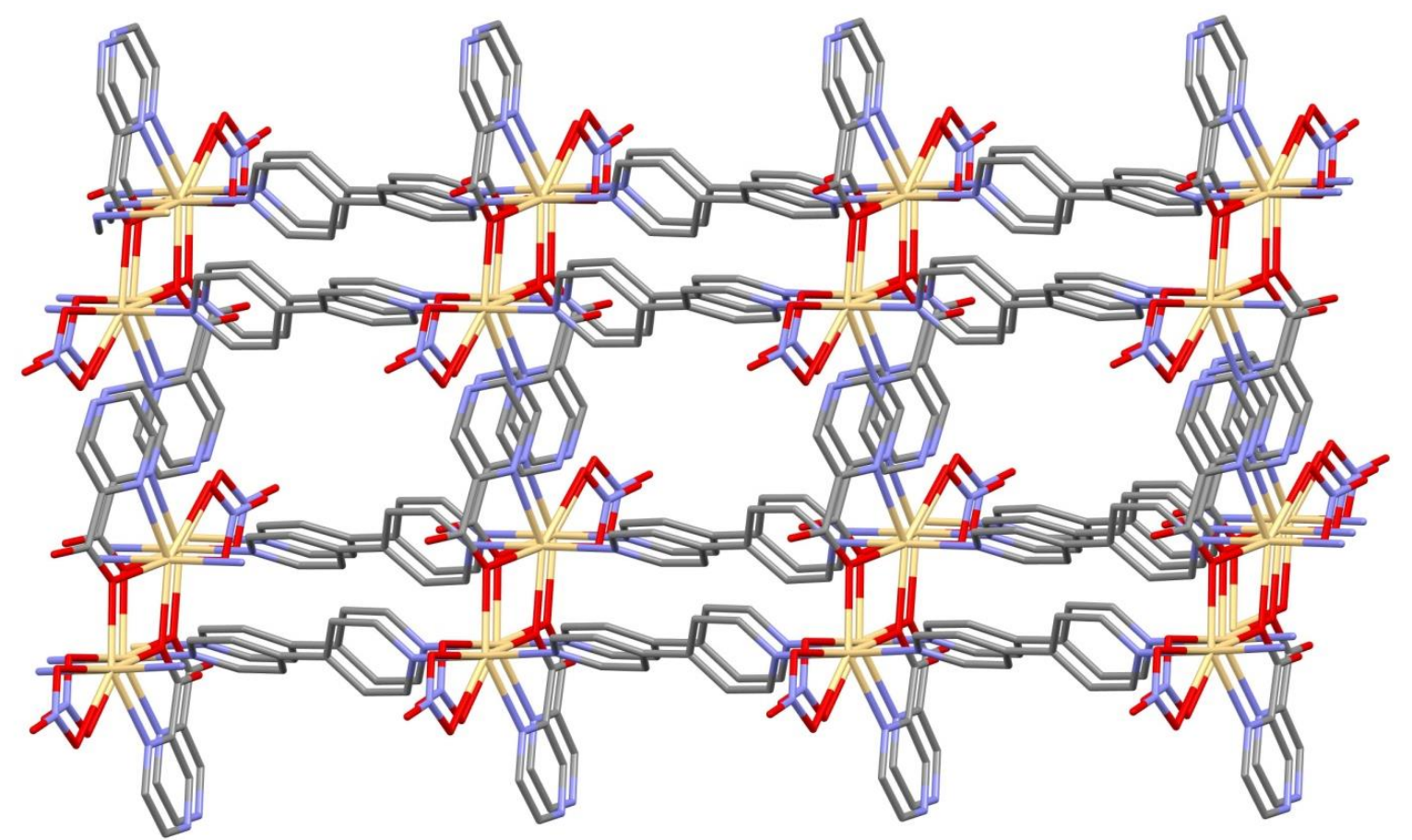

Fig. 10: One-Dimensional Channel Pores of Compound 1. 


\section{Conclusion}

In this paper, we describe a simple synthetic preparation of a novel coordination polymer. This method for preparation of coordination polymers has some advantages such as: taking places in shorter reaction times, producing better yields, producing the single crystal at high quality. The structure of polymer was confirmed by thermal stability, PXRD, FT-IR, and elemental analysis. This polymer was utilized as a sorbent for extraction of acetaminophen medicine. One of the advantages of this study is utilizing the coordination polymer as sorbent for extraction of acetaminophen medicine by the time-consuming and simple method. Furthermore, monitoring and determination of trace amount of medicine by UV-Vis spectrophotometer as inexpensive equipment is another benefit which we reach to it.

\section{Supplementary data}

CCDC 933939 contains the supplementary crystallographic data for compound 1. These data can be obtained free of charge via http://www.ccdc.cam.ac.uk/conts/retrieving.html, or from the Cambridge Crystallographic Data Centre, 12 Union Road, Cambridge CB2 1EZ, UK; fax: (+44) 1223-336-033; or e-mail:deposit@ccdc.cam.ac.uk.

\section{Acknowledgements}

The authors are thankful to the Chemistry Department of the Payam Noor and Shahid Beheshti University.

\section{References}

[1] M.G. Amiri, A. Morsali, A.D. Hunter, M. Zeller, Spectroscopy, thermal and structural studies of new ZnII coordination polymer, [Zn3 (mbpa) 4.5 (AcO) 3] (ClO4)3.4.26H2O, Solid State. Sci, 9 (2007) 1079-1084. http://dx.doi.org/10.1016/j.solidstatesciences.2007.07.016.

[2] S.I. Noro, S. Kitagawa, T. Akutagawa, T. Nakamura, Coordination Polymers constructed from transition metal ions and organic N-containing heterocyclic ligands: Crystal structures and microporous properties, Prog. Polym. Sci, $34 \quad$ (2009) $240-279$. http://dx.doi.org/10.1016/j.progpolymsci.2008.09.002.

[3] L. Hashemi, A. M orsali, Sonichemical Synthesis of a New Ethylene Diamine Lead(II) Coordination Polymer as Precursor for Preparation of PbO Nano-StructureCryst. Eng. Commun, 14 (2012) 779. http://dx.doi.org/10.1039/C2CE06133C.

[4] F. Jing Liu, D. Sun, H. Jun Hao, R.B. Huang, L.S. Zheng, Anion-controlled assembly of silver (I)/amonobenzonitrile compounds: syntheses, crystal structure, and photolumenecence properties, Cryst. Growth. Des, 12 (2012) 354. http://dx.doi.org/10.1021/cg201159z.

[5] A. Erxleben, "Structures and properties of $\mathrm{Zn}$ (II) coordination polymers", Coord. Chem. Rev, 246 (2003) 203. http://dx.doi.org/10.1016/S0010-8545(03)00117-6.

[6] M. Oh, C.A. Mirkin, Chemically tailorable colloidal particles from infinite coordination polymers. Nature, 438 (2005) 65. http://dx.doi.org/10.1038/nature04191.

[7] Y.-M. Jeon, G.S. Armatas, D. Kim, M.G. Kanatzidis, C.A. Mirkin, Tröger's-base-derived infinite coordination polymer microparticles, Small, 546 (2009). http://dx.doi.org/10.1002/smll.200801160.

[8] PJ. Hagrman, D. Hagrman, J. Zubiet, Organic-inorganic hybrid materials: from "Simple" coordination polymers to organodiamine-templated molybdenum oxides, Angew. Chem. Int. Ed, 38 (1999) 2638-2648. http://dx.doi.org/10.1002/(SICI)1521-3773(19990917)38:18<2638::AIDANIE2638>3.0.CO;2-4.

[9] X.M. Chem, M.L. Tong, Solvothermal in Situ Metal/Ligand Reactions: A New Bridge between Coordination Chemistry and Organic Synthetic Chemistry Acc. Chem. Res, 40 (2007) 162-170. http://dx.doi.org/10.1021/ar068084p.

[10] J.H. Liao, P.L. Chen, C.C. Hsu, "Syntheses and structure characterization of inorganic/organic coordinationpolymers: Ag (dpa), Co (O3PH) (4, 4 '-bpy) (H2O), Zn (O3PH) (4, 4 '-bpy) (0.5) and Mn [O2PH (C6H5)] (2), J. Phys. Chem. Slids, 62 (2001) 1629-1642. http://dx.doi.org/10.1016/S0022-3697(01)00101-9.

[11] S. Kitagawa, T. Okubo, S. Kawata, M. Kondo, M. Katada, H. Kobayashi, An oxalate-linked copper (II) coordination polymer, [Cu2 (oxalate) 2 (pyrazine) 3] n, constructed with two different copper units: X-ray crystallographic and electronic structures, Inorg. Chem, 34 (1995) 47904796. http://dx.doi.org/10.1021/ic00123a012.

[12] J.M.J. Paulusse, J.PJ. Huijbers, R.P. Sijbesma, Quantification of Ultrasound-Induced Chain Scission in PdII-Phosphine Coordination Polymers, Chem. Eur. J, 12, (2006) 4928-4934. http://dx.doi.org/10.1002/chem.200600120.

[13] J.M.J. Paulusse, R.P. Sijbesm, Reversible mechanochemistry of a PdII coordination polymer Angew. Chem. Int. Ed, 34 (2004) $4560-4562$ http://dx.doi.org/10.1002/ange.200460040.

[14] V.P. Balema, J.W. Wiench, M. Pruski, V.K. Pecharsky, Solvent-free mechanochemical synthesis of two Pt complexes: cis-( $\mathrm{Ph} 3 \mathrm{P}) \mathrm{PtCl} 2$ and cis-(Ph3P)PtCO3, Chem. Commun, (2002) 1606-1607. http://dx.doi.org/10.1039/b203694k.

[15] X. Xu, X. Liu, X. Zhang, T. Sun, Synthesis, characterization and property study of new coordination polymers constructed from flexible dicarboxylates and bidentate nitrogen mixed ligands Solid State Sci, $12 \quad$ (2010) 355-360. http://dx.doi.org/10.1016/j.solidstatesciences.2009.11.013.

[16] O.J. Garc1'a-Ricard, A.J. Herna'ndez-Maldonado, Cu2 (pyrazine-2, 3-dicarboxylate) 2 (4, 4'-bipyridine) Porous Coordination Sorbents: Activation Temperature, Textural Properties, and CO2 Adsorption at Low Pressure Range J. Phys. Chem C, 114 (2010) 1827-1834.

[17] A. Kondo, T. Daimaru, H. Noguchi, T. Ohba, K. Kaneko, H. Kanoh, Adsorption of water on three-dimensional pillared-layer metal organic frameworks, J. Colloid Interface Sci, 314 (2007) 422. http://dx.doi.org/10.1016/j.jcis.2007.05.090.

[18] M. Eddaoudi, J. Kim, N. Rosi, D. Vodak, J. Wachter, M. O'Keeffe, O.M. Yaghi, Systematic design of pore size and functionality in isoreticular MOFs and their application in methane storage, Science, 295 (2002) 469. http://dx.doi.org/10.1126/science.1067208.

[19] S. Bureekaew, S. Shimomura, S. Kitagawa, Chemistry and application of flexible porous coordination polymers, Sci. Technol. Adv. Mater, 9 (2008) 014108. http://dx.doi.org/10.1088/1468-6996/9/1/014108.

[20] C. Bicchi, C. Cordero, P. Rubiolo, P. Sandra, Impact of water/PDMS phase ratio, volume of PDMS, and sampling time on Stir Bar Sorptive Extraction (SBSE) recovery of some pesticides with different KO/W, J. Sep. Sci, 26 (2003) 1650. http://dx.doi.org/10.1002/jssc.200301613. 
[21] A. Morsali, M.Y. Masoom, Structures and properties of mercury (II) coordination polymers, Coord. Chem. Rev, 253 (2009) $1882-1905$. http://dx.doi.org/10.1016/j.ccr.2009.02.018.

[22] G. Burgot, F. Auffret, J.L. Burgot, Determination of acetaminophen by thermometric titrimetry, Anal. Chim. Acta, 343 (1997) 125-128. http://dx.doi.org/10.1016/S0003-2670(96)00613-7.

[23] A.B. Moreira, H.P.M. Oliveira, T.D.Z. Atvars, I.L.T. Dias, G.O. Neto, E.A.G. Zagatto, L.T. Kubota, Direct determination of paracetamol in powdered pharmaceutical samples by fluorescence spectroscopy, Anal. Chim. Acta, 539 (2005) 257-261[24] C. Nebot, S.W. Gibb, K.G. Boyd, Anal. Chim. Acta, 598 (2007) 87-94.

[24] X. Chen, J. Zhu, Q. Xi, W. Yang, A high performance electrochemical sensor for acetaminophen based on single-walled carbon nanotubegraphene nanosheet hybrid films, Sens. Actuators B, 161 (2012) 648- 654. http://dx.doi.org/10.1016/j.snb.2011.10.085.

[25] D.J. Speed, S.J. Dickson, E.R. Cairns, N.D. Kim, Analysis of paracetamol using solid-phase extraction, duterated internal standards, and gas chromatography -mass spectrometry,J. Anal. Toxyc, 25 (2001) 198-202. http://dx.doi.org/10.1093/jat/25.3.198.

[26] R.A. Horvitz, P.I. Jatiow, Determination of Acetaminophen concentration in serum by high-pressure liquid chromatography, CLIN. CHEM, 23/9 (1977) 1596-1598.

[27] S.G. Nelson, Z. Wan, M.A. Stan, SN2 Ring Opening of $\beta$-Lactones: An Alternative to Catalytic Asymmetric Conjugate Additions, J. Org. Chem, 67 (2002) 4680-4683. http://dx.doi.org/10.1021/jo025519n.

[28] Stoe\&Cie, X-AREA: Program for the Acquisition and Analysis of Data, (Version 1.30), Stoe\&Cie GmbH: Darmstadt, Germany (2005).

[29] G. M. Sheldrick. SHELX 97. Program for Crystal Structure Solution, University of Göttingen, Germany (1997).

[30] G. M. Sheldrick. SHELX 97. Program for Crystal Structure Refinement, University of Göttingen, Germany (1997).

[31] A.J.C. Wilson(Ed.). International Tables for X-ray Crystallography, Vol. C, Kluwer Academic Publisher, Dordrecht, Netherlands (1995).

[32] Stoe\&Cie, X-STEP32: Crystallographic Package, (Version 1.07b), Stoe\&Cie GmbH: Darmstadt, Germany (2000).

[33] A.Y. Robin, K.M. Fromm, Coordination polymer networks with O- and N-donors: What they are, why and how they are made, Coord. Chem. Rev, 250 (2006) 2127-2157. http://dx.doi.org/10.1016/j.ccr.2006.02.013.

[34] J-.H. Liao, C-Y. Lai, C-.D. Ho, C-.T. Su, Syntheses and characterization of two coordination polymers: [Cd(isonicotinate)2(H2O)] DMF and Cd3(isonicotinate)4 (NO3)2(4,4'-bipy)2(H2O)2 Inorg. Chem. Commun, 7 (2004) 402-404. http://dx.doi.org/10.1016/j.inoche.2003.12.012.

[35] P. Chutia, Sh. Kato, T. Kojima, Sh. Satokawa, Synthesis and characterization of $\mathrm{Co}(\mathrm{II})$ and $\mathrm{Cu}(\mathrm{II})$ supported complexes of $2-$ pyrazinecarboxylic acid for cyclohexene oxidation, Polyhedron, 28 (2009) 370-380. http://dx.doi.org/10.1016/j.poly.2008.10.063.

[36] Y-C. Liang, M-C. Hong, J-C. Liu. R. C, Hydrothermal syntheses, structural characterizations and magnetic properties of cobalt (II) and manganese (II) coordination polymeric complexes containing pyrazinecarboxylate ligand, Inorg. Chim. Act, 328 (2002) 152-158. http://dx.doi.org/10.1016/S0020-1693(01)00716-2.

[37] F. Zhang, L. Hao, L. Zhang, X. Zhang, Solid-State Thermolysis Preparation of Co3O4 Nano/Micro Superstructures From Metal-Organic Framework for Supercapacitors, Int. J. Electrochem. Sci, 6 (2011) 2943-2954.

[38] M. Sun, P. Wang, H. Zhou, J. Yang, J. Wu, Y. Tian, X. Tao, M. Jiang, 1D chain Cd(II) and Co(II) coordination polymers: Synthesis, crystal structures and luminescence properties J. Mol. Struct, 873 (2008) 73-78. http://dx.doi.org/10.1016/j.molstruc.2007.03.019. 